\title{
Pendekatan Eksplorasi pada Kasus Anak Oppositional Defiant Disorder di Kota Makassar
}

\section{Exploring Oppositional Defiant Disorder Study Case in Makassar}

\author{
Meily Lunanta Kouwagam, ${ }^{1)^{*}}$ Lita Patricia Lunanta ${ }^{2)^{*}}$ \\ 1) Sekolah Tinggi Filsafat Theologia Jaffray Makassar \\ *Penulis Korespondensi: meilylunanta@yahoo.com \\ 2) Fakultas Psikologi, Universitas Esa Unggul, Jakarta \\ *Penulis Korespondensi: litapatricialunanta@gmail.com
}

Received: 2610 2021/ Accepted: 2912 2021/ Published: 31122021

\begin{abstract}
Abstrak
Anak adalah karunia yang paling berharga bagi sebuah keluarga sehingga jika anak itu mengalami kelainan dalam berperilaku, orang tua perlu mencari solusi untuk mengatasi. Artikel ini bertujuan untuk mendeskripsikan, mengungkapkan, dan mencari solusi penanganan anak yang mengalami Oppositional Defiant Disorder (ODD). Pendekatan eksplorasi digunakan dengan metode wawancara dan dokumentasi untuk mengumpulkan data agar mendukung analisis holistik dalam rangka mencapai tujuan artikel ini. Data yang dikumpulkan terdiri atas dua jenis yaitu data primer dan data sekunder. Data primer diperoleh dari seorang anak yang mengalami gangguan ODD dan dilengkapi oleh data dari orang tua, pakar yang terkait topik ini. Sedangkan data sekunder dari hasil kajian sebelumnya terhadap lima kasus. Pola perilaku mereka menunjukkan perlawanan kepada otoritas baik orang tua maupun guru di sekolah. Kelima kasus dari data dokumentasi menunjukkan perilaku yang tidak menyukai peraturan, perkembangan emosional yang tidak stabil, dan pengendalian diri yang buruk. Solusi penanganan anak yang mengalami gangguan ini adalah memberikan pelatihan kepada orang tua, orang tua membuat aturan yang diterapkan secara konsisten, orang tua memberi penghargaan, dan melibatkan seluruh anggota keluarga dengan perspektif yang sama. Artikel ini merupakan studi kasus yang tidak digeneralisasi melainkan berusaha memberikan penggambaran yang holistic terhadap kasus yang ada.
\end{abstract}

Kata-kata Kunci: Anak Berkebutuhan Khusus, Eksplorasi, Emosional, Oppositional Defiant Disorder, Studi Kasus.

\section{Abstract}

Children are most precious gift to a family. Therefore, if there is a problem with a child, parents would want to find a way to treat them. This article aimed to describe, to explore and to find solution for children with oppositional defiant disorder (ODD). 
Interviews and documentations are used to get a holistic view of the problem. Datas that are collected were primary data and secondary datas. The primary data was from one child with oppositional defiant disorder and his parents along with his psychological records. Secondary datas are previous cases about similar struggle in children. The result showed a pattern of oppositional behavior to authority, to parents and teachers at school. Secondary case also showed a pattern of defiant behavior, unstable emotional development, and low self control. Treatment plan for oppositional defiant disorder case included giving a training for parents so they can apply aconsistent rules while giving a positive regard, and involving all family members to work in the same framework. This article is a study case that was not meant to be generalize but aim to describe the case from various point of view, theologically and psychologically.

Keywords: Case Study, Emotional, Exploration, Oppositional Defiant Disorder, Special Need.

\section{PENDAHULUAN}

Anak adalah berkat dan pusaka dari Tuhan lewat kandungan seorang ibu yang memiliki cinta dan kasih sayang dengan suaminya. Cinta dan kasih sayang itu pun sesungguhnya bersumber dari Allah Sang Pengasih dan sumber cinta yang menciptakan manusia. Kehadiran manusia sebagai pria dan wanita telah menjadi rancangan Allah untuk beranak cucu turun temurun dan anak-anak ini adalah mahkota karena dirancang oleh Alla. Bahkan di dalam Kitab Amsal dinyatakan bahwa "Mahkota orang-orang tua adalah anak cucu dan kehormatan anak-anak ialah nenek moyang mereka" (Ams. 17:6).

Anak-anak sebagai mahkota menjadi perhatian yang serius bagi setiap orang tua lewat bimbingan dan pemeliharaan yang dilakukan setiap saat. Perhatian dan pemeliharaan itu dilakukan agar pertumbuhan mahkota orang tua tersebut memberi suka cita karena anak-anak yang dipercayakan Tuhan memiliki perilaku yang baik dan hidup dalam jalan yang benar. Bersuka cita dan beria-rialah ayah dan ibu yang melahirkan anak-anak yang bijak (Bdk. Ams. 23:24-25) dan kebijakan yang dimiliki oleh anak-anak ini tentu menjadi karunia Tuhan lewat tuntunan orang tua. Para orang tua juga merasa sangat bahagia bila anak-anak yang dilahirkan selalu bertutur kata yang jujur dan bijak (Bdk. Ams. 23:15-16).

Anak-anak sejak dini juga perlu dibina. Proses pembinaan tentu akan sangat tergantung pada juga pada kesehatan atau kondisi normal fisik dan psikis anak-anak itu. Sebagai contoh, Nixon (2009) mencatat bahwa kondisi anak-anak yang dihadapi oleh orang tua tentu memiliki persoalan atau permasalah yang berbeda-beda sehingga orang tua anak yang bersangkutan pun sudah pasti menghadapi secara 
berbeda. Ridha (2019) menyatakan bahwa perilaku anak-anak yang ditandai dengan ketidakmampuan dalam mengontrol diri, tidak patuh, menantang, dan menunjukkan perilaku mengganggu dalam lingkungan sosial biasa disebut Oppositional Defiant Disorder (ODD). Kerap kali, anak-anak yang termasuk ODD ini bisa dikenal sebagai "anak nakal" atau "anak pembangkang" karena tidak mau mengikuti aturan atau tata krama yang disampaikan oleh orang tua, guru atau orang dewasa dan yang lain.

Perilaku membangkang pada anak-anak ini kerapkali membuat orang tua sulit mengatasi dan bahkan ada dari anak-anak ODD yang mengamuk, melempar bendabenda atau menyerang orang tua mereka. Guru-guru di sekolah juga merasa kewalahan menangani karena bukan hanya melawan tetapi juga sulit ditertibkan saat proses belajar di mana anak ini juga tidak mau duduk dengan tenang bahkan mengganggu temannya yang akan serius belajar. Hal ini yang dibahas oleh Jones dalam artikelnya mengenai kasus ODD dalam konteks guru dan murid (Jones, 2017, p. 12). Tidak sedikit guru akhirnya menggunakan kontak fisik dan menyakiti anak didik - seperti yang dicatatkan dalam penelitian Alurmei pada guru-guru Al-Falaah, Tangerang Selatan (2019, p. 323). Kondisi ini yang menjadi kekhawatiran orang tuanya karena perilaku yang sulit diatur dan mengganggu orang sekitarnya. Perilaku anak ODD ini memang menjadi masalah bagi orang tua yang memiliki anak seperti ini karena orang tua yang bersangkutan perlu memberikan intervensi berupa dukungan perilaku positif agar dapat berubah secara perlahan (Ridha, 2020). Perilaku anak seperti ini perlu digambarkan kondisi yang dialami oleh setiap anak. Bagaimana sudut pandang psikologis dan teologis mengenai kondisi anak seperti ini dan secara lebih spesifik bagaimana implementasi konseling yang berlatar belakang Kristiani. Artikel ini bertujuan untuk mendeskripsikan, mengungkapkan, dan mencari solusi penanganan anak yang mengalami Oppositional Defiant Disorder berdasarkan konseling Kristiani.

\section{TEORI}

Konsep dasar mengenai Oppositional Defiant Disorder ini akan dijelaskan secara berurutan mengenai karakteristik ODD, kenakalan semu, kenakalan sebenarnya, pandangan psikologis, pandangan teologis, dinamika, dan penanganan ODD.

\section{Karakteristik Oppositional Defiant Disorder}

Anak-anak yang didiagnosis kategori Oppositional Defiant Disorder ini karena mengalami gangguan emosional dan perilaku agresif dalam proses perkembangan (Geral Corey, 2009). Dalam artikel Schoorl dan kawan-kawan terbukti juga bahwa disregulasi emosi menjadi salah satu faktor pemicu (Schoorl dkk, 2016, p. 1). Seorang anak yang gagal menggunakan semua milik pribadinya untuk beradaptasi dengan baik akan sulit terkontrol pertumbuhannya jika tidak ditangani (Rebecca P. Ang, 2004). Menurut Kane dan Garber (2004) suatu perilaku dapat dikategorikan sebagai anak mengalami ODD bila memiliki faktor intensitas perilaku ODD, frekuensi 
berperilaku ODD, durasi perilaku, dan pola atau gejala perilaku yang ditunjukkan sebagai anak ODD.

Menurut Yulia Singgih Gunarsa (2012), terdapat beraneka ragam tingkah laku anak yang sering menimbulkan kekesalan dan kekhawatiran pada seseorang, walaupun bagi orang lain belum merupakan suatu hal yang memerlukan pemikiran lebih mendalam. Proses untuk mengubah anak yang mengalami gejala ini disesuaikan dengan tingkat perilaku anak mulai dari yang derajat ringan sampai pada derajat kesulitan yang berat. Karakteristik anak ODD ini memang terlihat jelas pada perilaku yang sulit beradaptasi di mana kemauannya saja yang harus terjadi. Hal ini juga dibuktikan oleh penelitian Sanjiwani di sebuah panti asuhan (Sanjiwani dkk, 2020, p. 1). Selain itu anak ODD juga mudah dibedakan dengan temannya bila terjadi intensitas, frekuensi, durasi, dan pola perilaku yang ditunjukkan sebagai anak ODD. Dalam contoh kasus penelitian yang dilakukan oleh Rochmah, anak dengan ODD membangkang/menentang, melakukan perilaku negatif, melakukan permusuhan dan agresi verbal yang dapat terjadi kapan saja dengan objeknya orang dewasa, teman atau peraturan $(2018$, p. 3.938).

\section{Kenakalan Semu}

Bahasa sehari-hari menyebut kenakalan bahkan ada yang dinyatakan keterlaluan, padahal sebenarnya anak tersebut masih berperilaku dalam batas-batas normal. Kerap kali orang tua terlalu khawatir dan salah dalam menilai anak mereka sehingga alamat ODD pun biasa disematkan pada anak-anak yang masih dikategorikan berperilaku normal. Kebiasaan orang tua ini yang menimbulkan kenakalan semu karena sebenarnya anak mereka masih bisa dikategorikan normal tetapi orang tua mereka yang berlebihan. Akibat dari hal ini adalah anak-anak akan melakukan usahan untuk membebaskan diri dari kekangan tersebut dengan cara mempertahankan perilaku sebagai reaksi pada sikap orang tua. Terjadinya kenakalan anak-anak di sekolah sebagai contoh, dapat menimbulkan kenakalan semu ketika muncul perkelahian anak-anak karena aturan sekolah tidak tersosialisasi dengan baik.

\section{Kenakalan Sebenarnya}

Tingkah laku yang melanggar nilai-nilai sosial dan moral sehingga merugikan diri sendiri dan orang lain biasanya dikenal sebagai kenakalan sebenarnya. Gangguan perilaku ini sering mengkhawatirkan dan menimbukan kegelisahan, misalnya anak yang sering berbohong dan mencuri.

Kriteria diagnostik anak-anak ODD menurut American Psychiatric Association (2000) antara lain pertama, menunjukkan suatu pola perilaku negatif, keras, dan melawan selama lebih dari enam bulan. Kedua, gangguan perilaku yang ditunjukkan menyebabkan suatu kelumpuhan/kegagalan yang signifikan dalam relasi sosial, kehidupan akademis, atau dalam dunia pekerjaan. Ketiga, gangguan perilaku tidak muncul hanya bersamaan dengan munculnya gangguan psikosis atau mood. Keempat, kriteria yang ada tidak memenuhi syarat pada conduct diorder, dan apabila 
usia individu lebih dari 18 tahun, maka tidak memenuhi kriteria Antisocial Personality Disorder.

Selain kriteria yang diungkapkan American Psychiatric Association, terdapat karakteristik-karakteristik yang berkaitan dengan gangguan perilaku ODD. Sebagai contoh gangguan dari dalam diri anak itu sendiri, keluarga, teman sebaya, sekolah, dan masyarakat nampaknya terjadi seiring peningkatan perilaku ODD. Secara lebih detail karakteristik yang diungkapkan oleh E. J. Mash dan D. A. Wolfe (1999) antara lain gangguan dalam kognisi dan belajar, gangguan dalam harga diri, gangguan interpersonal dengan teman sebaya, gangguan sosial-kognitif, gangguan dalam keluarga, dan masalah yang berkaitan dengan kesehatan.

\section{Pandangan Psikologis terhadap Oppositional Defiant Disorder}

Gangguan ODD pada anak-anak diperkirakan telah disebabkan oleh kombinasi dari faktor biologis, psikologis, dan sosial. Berdasarkan faktor Biologis, temperamen yang sulit saat bayi tergambar dalam impulsifitas, labilitas emosional, ketidakgigihan dalam pemecahan masalah, perilaku tidak dapat diam, negativitas, dan sensitifitas terhadap stress yang ditunjukkan saat masa kanak-kanak (Caspi, Henry, Mc-Gee, Moffitt, dan Silva, 1995; Ghosh, Ray \& Basu, 2017, p. 364). Lebih jauh, terdapat penelitian yang menemukan bahwa temperamen yang seperti ini pada masa kanakkanak berkaitan dengan perilaku kekerasan yang dilakukan pada masa remaja dan dewasa (Farrington, 1989; Henry, Caspi, Moffitt, dan Silva, 1996).

Sedangkan faktor genetik, meskipun perilaku antisisial bukan merupakan perilaku keturunan, namun kepribadian yang berbasis biologi, seperti temperamen impulsif, dipengaruhi oleh faktor herediter. Fakta menunjukkan bahwa perilaku agresif dan antisosial terjadi pada beberapa anggota keluarga, baik dalam generasi yang sama maupun pada generasi selanjutnya. Faktor neurobiologis memiliki dampak juga terhadap masalah perilaku anak khususnya perilaku agresif sebagaimana ditemukan dalam penelitian di bidang neurochemistry, neuroimagery, meurodevelopmental, peripheral psychophysiology, dan neuropshychology (Lahey dkk, 1994; Raine, 1993). Faktor genetik juga diakui oleh Mikolajewski dan kawan-kawan dalam artikel mereka. ODD menyebabkan banyaknya gangguan mental pada masa kecil. Namun, lebih jauh lagi, faktor genetik mendorong perilaku anti-sosial, mudah tersinggung dan keras kepala (Mikolajewski, Amy J., 2017, p. 702). Anak dengan gangguan perilaku menunjukkan perbedaan dengan anak yang normal dalam dua hal yaitu pertama, mereka menunjukkan rendahnya psychophysiological arousal dan cortical arousal dan kedua, mereka menunjukkan reaktivitas otonom yang rendah, misalnya dalam detak jantung.

Berdasarkan faktor sosial-kognitif, menurut Mash dan Wolfe (1999) bahwa terdapat beberapa teori yang menghubungkan cara berpikir anak dengan perilaku agresif yang mereka lakukan seperti pendekatan kognitif-struktural yang menenkankan pada proses berpikir tidak dewasa, egosentrisme, dan ketidakmampuan untuk memahami pemikiran orang lain (Selman, Beardslee, Schlutz, 
Krupa, dan Poderefshy, 1986; Selman dkk., 1992; Mash dan Wolfe, 1999). Kemudian pendekatan kognitif-perilaku yang menekankan pada keterbatasan kognitif, misalnya ketidak mampuan anak untuk menggunakan komunikasi verbal yang baik ketika berselisih (Mash dan Wolfe, 1999). Akhirnya pendekatan proses informasi sosial yang menekankan pada distorsi kognitif, misalnya interpretasi negatif yang diberikan anak kepada suatu situasi netral (Crick dan Dodge, 1994).

Sementara itu, berdasarkan faktor keluarga yang memiliki banyak aspek yang dapat dihubungkan dengan perilaku anak yang buruk, seperti konflik perkawinan, isolasi keluarga, kekerasan dalam rumah, penggunaan disiplin yang keras atau inkonsisten, tidak adanya pengawasan orang tua, tidak adanya dukungan emosional, dan dominasi yang berlebihan dari salah satu anggota keluarga (Frick, 1993; Hinshaw dan Anderson, 1996; Mash dan Wolfe, 1999).

Faktor sosial, yang berpengaruh adalah bagaimana situasi sosial di sekitar rumah anak dan bagaimana kondisi sekolah di mana anak belajar. Demikian juga dengan faktor budaya dan etnisitas yang dapat mempengaruhi ekspresi agresifitas yang diungkapkan anak.

\section{Pandangan Teologis terhadap Oppositional Defiant Disorder}

Secara sepintas dilihat bahwa persoalan yang terjadi pada masa modern ini seringkali dianggap bahwa di luar dari konteks Alkitab sehingga jawabannya tidak ada di dalam Kitab Suci. Namun jika kita melihat secara lebih dalam, maka muncul dengan jelas bahwa permasalah yang dialami sekarang ini juga kerap kali dialami oleh orang-orang dari masa ke masa seperti dalam Kitab Perjanjian Lama dan Perjanjian Baru di dalam Alkitab. Sebagai contoh, manusia pertama Adam dan Hawa mengalami tantangan dalam mendidik anaknya di mana Kain membunuh Habel. Yang pasti bahwa banyak kondisi keluarga yang dialami menjadi gambaran yang serupa dengan kondisi keluarga saat ini khususnya dalam menyelesaikan masalah anak-anak mereka. Jadi berdasarkan pandangan teologis bahwa kondisi yang dialami sekarang ini pun dialami pada masa-masa sebelumnya bahkan pada manusia pertam sekalipun.

\section{Dinamika Oppositional Defiant Disorder}

Anak-anak ODD sebenarnya berperilaku membangkan, melawan, menyebalkan dan lain-lain adalah bukan karena faktor anak-anak itu sendiri tetapi dapat kita lihat juga bahwa sebenarnya manusia pada dasarnya adalah orang berdosa. Perilaku membangkang sebenarnya dilakukan oleh orang yang sering berbuat buruk dan dibuktikan oleh manusia pertama yang juga membangkang pada perintah Allah. Melalui Adam, dosa masuk ke dunia dan mempengaruhi manusia (Bdk. Rom. 5:12). Jadi dosa sebagai kuasa yang aktif memasuki umat manusia sehingga jauh dari Tuhan (Bdk. Rom. 5:17-9: Kej. 3; 1 Kor. 15:21-22).

Donald C. Stamps (1994) mengatakan bahwa manusia yang lahir ke dunia ini cenderung berbuat dosa karena akibat dari dosa asal. Dosa dan kecemasa memasuki 
hati dan kehidupan Adam dan seterusnya berlanjut kepada semua manusia. Secara logik juga dapat dilihat bagaimana Adam dan Hawa yang anaknya Kain membunuh Habel.

Kondisi manusia sekarang ini pun makin diperpara oleh berbagai faktor yang menyebabkan perilaku manusia sangat berkembang baik yang perilaku baik maupun yang buruk. Kondisi ketidak berdayaan manusia ini dilihat oleh kekuatan dosa yang menggoda manusia untuk berperilaku yang tidak buruk. Baik anak-anak maupun orang dewasa cenderung menjauh dari Tuhan dan berbuat tidak ada rasa takut lagi kepada Tuhan.

\section{Penanganan Oppositional Defiant Disorder}

Upaya untuk menangani anak-anak yang dikategorikan mengalami masalah ODD ini tentu perlu tindakan yang dilakukan untuk mengintervensi agar perilaku yang agresif, menyebalkan dan perilaku lainnya dapat dikendalikan. Anak-anak ODD yang tanpa kendali bisa saja berlanjut menjadi anak-anak conduct disorder. Lebih lanjut lagi, Lester (2002) menegaskan bahwa banyak masalah emosi, relasi dan rohani yang diderita orang dewasa yang merupakan akibat dari krisis masa kanak-kanak yang tidak diselesaikan dengan kreatif.

Saran pertama yang dapat dilakukan adalah Positive Behavior Support. Penelitian ini dilakukan oleh Ridha dan menuai perubahan positif terhadap anak dengan ODD (2020, p. 150). Berdasarkan Matthys \& Lochman (dalam Ridha, 2020, p. 152), Positive Behavior Support adalah pendekatan dengan tujuan meningkatkan fungsi akademik dan sosial yang positif dalam lingkungan sekolah.

Selain itu, perlu dilakukan sebuah evaluasi untuk memahami secara komprehensif gangguan bagi anak-anak ODD dan gangguan lain yang muncul akibat masalah ODD ini seperti Attantion-Deficit Hyperactive Disorder (ADHD), gangguan belajar, gangguan mood (depresi, bipolar disorder), dan gangguan kecemasan. Sulit menangani anak-anak ODD jika masalah yang muncul bersamaan dengan itu tidak ditangani juga dengan baik. Selain itu, penanganan yang baik adalah penanganan yang dirancang sesuai dengan kondisi anak dan keluarga yang menemani akan ODD. Kondisi yang dimaksudkan adalah usia anak, tingkat keparahan masalah, tujuan yang hendak dicapai, bantuan terdapat dalam keluarga dan lingkungan sekitar, serta situasi keluarga. Intervensi harus dilakukan selama durasi waktu tertentu (beberapa bulan atau lebih) dan kemungkinan memerlukan beberapa kali pengulangan.

Ada dua intervensi psikologis yang umum diberikan kepada anak ODD, yaitu pendekatan individual dan pendekatan keluarga. Pendekatan secara individual diberikan dalam bentuk problem-solving skills dan social problem-solving skills. Sedangkan pendekatan keluarga dilakukan dengan cara parent management training seperti pelatihan bagi orang tua untuk menerapkan teknik disiplin yang efektif dan bentuk-bentuk pengawasan yang sesuai dengan usia anak. Secara lebih spesifik, bentuk intervensi psikologis ini diberikan dalam bentuk: parent-management training, 
cognitive problem-solving skills, multisystem treatment, medications, dan preventive interventions.

Pandangan keilmuan psikologis dan teologis tentu diperlukan dalam penanganan anak ODD karena selain pendekatan keilmuan dalam bentuk empiris dari pandangan psikologis, juga sangat penting pendekatan teologis di mana Firman Tuhan dijadikan senjata utama dalam menghadapi masalah apapun di dunia ini. Secara ringkas konsep ini dituangkan dalam gambar berikut.

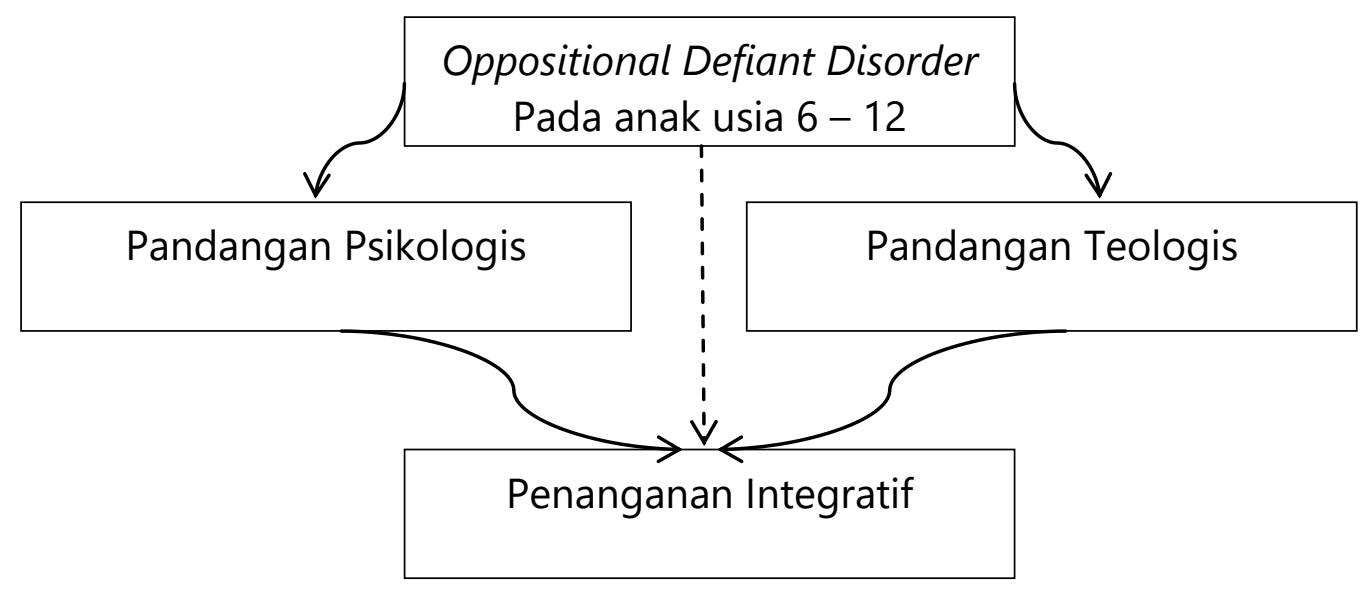

Gambar 1. Kerangka Berpikir

Pengaplikasian ilmu psikologis secara mutlak tanpa pendekatan lain seperti pandangan teologis adalah tidak benar dan juga tidak benar jika mengabaikan pendekatan keilmuan psikologis dalam menangani masalah anak-anak yang termasuk kategori ODD.

\section{METODE}

\section{Desain dan Subjek Penelitian}

Penelitian ini adalah suatu studi kasus yang fokus dalam suatu kejadian baik itu mencakup individu, kelompok budaya atau potret kehidupan (Creswell, 2013). Menurut Creswell (2013) bahwa ada beberapa karakteristik studi kasus yaitu mengidentifikasi kasus itu sendiri, kasus itu sebagai sebuah sistem yang terkait, dan perlu sumber informasi untuk mendapatkan data yang komprehensif. Studi kasus ini bertujuan mengeksplor apa sebenarnya yang terjadi pada unit analisis atau subjek penelitian yaitu seorang anak yang berinisial nama " $F$ ". Anak ini berumur tujuh tahun dan sedang mengenyam pendidikan di sekolah dasar, dan secara psikologis telah didiagnosis mengalami ODD. Selain itu, penelitian ini juga melengkapi datanya lewat kasus-kasus yang telah dibahas pada penelitian yang lain.

Metode pengumpulan data menggunakan metode wawancara untuk kasus anak ODD. Wawancara adalah tanya jawab atau percakapan yang diarahkan untuk 
mengumpulkan data yang berkaitan dengan topik yang diteliti, dan bermaksud melakukan eksplorasi untuk mencapai tujuan penelitian (Banister dkk., 1994; Creswell, 2014). Metode wawancara yang digunakan dalam penelitian ini adalah wawancara dalam bentuk percakapan yang informal di mana prosesnya mengalir sesuai dengan minat dan perhatian bahkan lewat berbagai aktivitas yang berkti (Patton, 1990).

\section{Teknik Analisis Data}

Analisis studi kasus dapat dibedakan atas dua jenis yaitu analisis holistik terhadap kasus dan analisis terhadap aspek tertentu dari kasus (Yin, 1989). Penelitian ini menggunakan analisis holistik yang bersifat menyeluruh dan membahas seluruh aspek yang ada dari kasus. Setelah menggambarkan secara holistik, kajian dilakukan lebih terperinci pada beberapa kata kunci atau tema yang terdapat di balik kasus, yang dilakukan untuk menggeneralisir, mengungkapkan kompleksitas kasus. Penelitian dengan studi kasus bisa datanya tunggal atau kasusnya jamak atau banyak. Penelitian ini menggunakan data primer dengan kasus tunggal untuk dikaji dan data sekunder lima kasus yang merupakan data dari penelitian sebelumnya.

\section{HASIL DAN PEMBAHASAN}

Hasil penelitian ini dimulai dari pengungkapan identitas subjek, gambaran subjek penelitian dan kasus dari literatur, perbandingan kasus, analisis data dan pembahasan.

\section{Identitas Subjek}

Identitas dari data primer adalah Faisal Rahman $(F)$ yang berjenis kelamin lakilaki, berumur tujuh tahun dan merupakan anak tunggal. Ayak anak ini bekerja sebagai wiraswasta (mengurus visa, paspor dan lain-lain), sedangkan ibunya bekerja sebagai karyawan departemen store. Keluarga dari subjek ini dimulai dengan pertemuan ayah dan ibu yang sama-sama belum pernah menikah dalam usia yang matang karena sang ayah berusia 30 tahun dan ibu berusia 25 tahun.

Penelitian ini juga melengkapi subjek penelitian dari lima studi kasus pada literatur. Keenam kasus dari literatur ini akan diidentifikasi secara singkat seperti berikut; pertama, Mattaew (Matt) adalah laki-laki yang berusia enam tahun dan anak kedua dari dua bersaudara (Anne Fraser, 2008). Kedua, Alex juga lahir dari keluarga yang memiliki dua anak, laki-laki berusia tujuh tahun dan merupakan anak kedua (Maryellen Soriano, 2006). Ketiga, Claire adalah anak perempuan berumur delapan tahun dari tiga bersaudara dan juga anak kedua (Rothenberg, 2013). Keempat, Eric adalah anak laki-laki yang berusia tujuh tahun yang lahir dari keluarga sebagai anak tunggal (Costin dan Chambers, 2007). Kelima, Marco sebagai anak laki-laki berumur sepuluh tahun dan anak kedua dari tiga bersaudara (Surbakti, 2012). Upaya untuk menggambarkan kondisi subjek penelitian akan diuraikan satu per satu dari kasus tersebut. 


\section{Kasus F}

Orang tua F mengelu karena anak ini sulit diatur dalam kegiatan sehari-hari dan dalam kegiatan belajar. la seringkali bersikap agresif (memukul dan menendang) dalam berinteraksi dengan orang lain, serta tidak dapat bersikap tenang. Orang tua $\mathrm{F}$ mengungkapkan bahwa anak ini memiliki pengendalian diri yang kurang baik. Sebagai contoh $\mathrm{F}$ yang mudah marah dan cemburu ini akan berlaku agresif seperti berbicara kasar atau kata-kata menyebut nama binatang. Lebih lanjut diungkapkan orang tua $\mathrm{F}$ bahwa anak ini memiliki perkembangan sosial yang buruk dan tidak memiliki teman dekat. Apabila $\mathrm{F}$ bermain dengan teman-temannya, maka $\mathrm{F}$ ini tidak mau menerima kekalahan dan biasa mengamuk kalau dikalahkan dan bahkan terlibat perkelahian. Selain itu, F ini malas dan sulit diatur untuk belajar serta tidak memiliki sopan santun kepada orang yang lebih dewasa dan juga kepada gurunya. Orang tua $\mathrm{F}$ sering berselisi paham dalam menangani $\mathrm{F}$ dan bahkan sulit menentukan pola yang tepat untuk menangani F. Ayah F memang sering moderat dan bahkan menegur ibu yang tegas kepada $\mathrm{F}$ dan ibu sesekali memukul atau mencubit.

Sebenarnya, F ini tinggal bersama dengan nenek, kakek, paman, dan tante. Sementara ibu hanya bertemu $F$ pagi hari sebelum masuk sekolah dan enam kali sebulan ketika ibu libur kerja. Pola pengasuhan F dibawa kendali nenek walaupun kerap kali tidak sependapat dengan ibu kandungnya dan ayah justru taat pada nenek.

Sedangkan kondisi sekolah, $F$ ini juga mendapat keluhan di sekolah dan $F$ merasa akan dikeluarkan karena dianggap sulit diatur di dalam kelas, tidak tertib dan mengganggu saat pelajaran dimulai. Anak $F$ ini merasa bahwa justru teman-teman sekolahnya yang sering mengganggu sehingga $F$ melakukan pemukulan atau menendang walaupun dia mengetahui bahwa hal itu membawa kerugian karena akan dimahari oleh guru-guru, kepala sekolah atau orang tua di rumah. Keluhan lain di sekolah tentang $\mathrm{F}$ ini adalah anak ini tidak memperhatikan apalagi mengikuti apa yang disampaikan guru-guru.

\section{Kasus dari Literatur}

Bahan kajian dari literatur ada lima kasus dan akan diuraikan datanya seperti berikut ini. Pertama, Matt memiliki sikap yang tidak mau diatur, mudah menangis dan sulit menenankan, mengalami depresi saat 18 bulan, setiap hari berkelahi dengan kakak saudaranya, kondisi ayah Matt sering marah karena tidak memiliki pekerjaan dan kesulitan finansial, orang tua kewalahan menangani. Sedangkan kondisi di sekolah, Matt tidak mengikuti instruksi di kelas di mana dia selalu mengganggu teman, mengintimidasi teman, sebenarnya Matt dapat mengerjakan pekerjaannya tetapi keras kepala dan menolak terlibat kegiatan sekolah serta sering berkeliling sambil cubit teman-temannya.

Kedua, Alex sulit tidur sewaktu masih bayi dan digendong terus, memiliki keinginan yang kuat dan sangat mudah menolak jika diminta melakukan sesuatu. Sulit mengatur diri, yang direncanakan tidak sesuai aturan, dia sangat superaktif, dan tidak mau mengatur kembali mainannya jika sudah selesai digunakan, tidak mau 
mendengar apa yang disampaikan orang tuanya, melawan otoritas, tidak mau tidur sendiri, dan perilakunya yang buruk sangat mengganggu fungsinya sehari-hari baik di rumah maupun di sekolah. Kebiasaan Alex di sekolah adalah suka mengganggu teman-temannya, dia sering menarik diri dari kegiatan sosial dan sering berada dalam kondisi emosional yang negatif. Alex tidak mengenal privasi orang lain, sering lari dan menabrak teman-temannya. Alex sudah didiagnosis ODD dan guru-gurunya memberikan perlakuan yang dapat membangun aspek positif dari dirinya agar bisa berubah. Guru memberikan apresiasi dan pujian ketika Alex menunjukkan keinginan untuk bekerja sama. Guru mengharapkan agar orang tua memberikan batasan yang konsisten bila Alex berbuat tidak sesuai aturan.

Ketiga, Claire yang memberi kesan pertama yang menyenangkan, mempesona, percaya diri yang tinggi. la memberi respon dengan baik dan terlibat dalam kegiatan. Claire bercerita mengenai sekolahnya, temannya, dan warna pelangi serta suka menjadi pusat perhatian bahkan di kantor dokter sekalipun. Orang tua mengantarnya ke dokter karena eksim kulit dan konstipasi kronis, di mana dia sering menggaruk tanpa henti terutama ketika dia lagi emosi. Claire hanya dua sampai tiga kali buang air besar dalam seminggu dengan usaha yang sangat keras. Komunikasi Claire dengan ibunya tidak baik karena ia membangkang sejak pagi hingga mau tidur malam. Claire sering merengek, berteriak, mengamuk dan mengajak kakak adiknya berkelahi. la sangat sensitif terhadap semua macam input sensoris seperti suara, cahaya, dan sentuhan. la tidak mentoleris kritikan atau saran orang, tidak suka melihat perubahan cahaya, dan kerap marah karena cara orang memandangnya atau menyentuhnya. Di sekolah Claire saat menit awal sangat rajin membantu dan kooperatif tetapi tiba-tiba bisa berubah merusak, tidak menuruti guru, dan berperilaku tidak tepat. Dia sangat mudah diarahkan dari sisi akademis tetapi soal interaksi dengan teman dan guru sangat sensitif dan sulit diarahkan. Dokter mendiagnosis Claire sebagai anak ODD dan memberikan treatment penanganan. Akhirnya orang tua Claire menceritakan bahwa kondisinya mulai membaik dan sudah menurun durasi perilaku ODDnya.

Keempat, Eric mengatakan bahwa sekolahnya menyebalkan dan dia tidak mau disuruh-suruh lagi. la beralasan bahwa nilai merah yang diperoleh karena ulah temannya dan dia saat itu keluar kelas sambil menjatuhkan buku-buku di atas meja gurunya. la sering mengganggu dan mengajak temannya berkelahi. Kasus Eric ini sudah dilakukan penanganan Parent Management Training (PMT) agar kondisinya berangsur membaik. Terapi ini sukses membantu anak ODD dan setelah delapan sesi pelatihan, maka nampak hasilnya yang signifikan. Eric mulai dapat mengendalikan perilaku, tidak cepat frustasi, dan dapat menunda reaksi marah.

Kelima, Marco yang selalu membuat orang tua dan gurunya kewalahan menghadapi karena selain keras kepala, ia juga sering membuat keributan di sekolah dengan mengganggu teman-temannya dan kelihatannya ia menikmati perbuatannya itu. Prestasinya dalam dunia akademik memang buruk karena hampir semua mata pelajaran nilainya rendah sehingga setiap menerima rapor, pasti orang tuanya 
dipanggil oleh pihak sekolah. Marco sering membuat onar, sembunyikan buku teman, mencorat-coret bangku dan papan tulis dan melempar-lempar kertas kepada teman saat guru mengajar. Intinya bahwa Marco cenderung selalu memberontak, membangkang, menentang dan sama sekali tidak mau mendengarkan nasihat gurunya. Sedangkan di rumah, Marco kurang mendapatkan perhatian karena kedua orang tuanya sibuk bekerja dari pagi sampai sore, bahkan malam dan tampaknya lebih mengejar karier daripada mendidik anak. Lebih lanjut ditemukan bahwa ayahnya tidak memiliki hubungan emosional dengan bapaknya karena ketika ayah Marco masih dalam kandungan maka bapaknya meninggal sehingga inspirasi pendampingan ayah tidak dimainkan untuk Marco. Pola pengasuhan anak seperti ini memang tidak mendukung pertumbuhan yang sebenarnya untuk Marco dan hanya ibu kandung saja yang selau mendampingi.

\section{Pembahasan}

Bagian ini akan diuraikan perbandingan kasus dari sisi gambaran umum, pola perilaku, penyebab ODD, dinamika ODD, penanganan ODD, dan hasil diagnosis psikologi serta pembahasan.

\section{Perbandingan Kasus}

Identitas subjek penelitian dan kelima kasus yang diamati menunjukkan bahwa subjek $\mathrm{F}$ dan keempat dari lima kasus pada studi literatur tersebut adalah lakik-laki dengan susunan anggota keluarga yang bervariasi, ada anak tunggal ( $F$ dan Eric), anak bunagsu (Matt dan Alex), serta anak kedua dari tiga bersaudara (Clairen dan Marco). Jika dilihat dari urutan struktur dalam keluarga, maka faktor ini tidak memberi dampak pada munculnya gangguan perilaku anak karena baik anak tunggal, anak tengah dan anak bungsu pun dapat mengalami hal yang sama.

Pola perilaku $F$ dan kelima subjek yang diamati dalam studi kasus ini menunjukkan bahwa setiap subjek melakukan perlawanan terhadap otoritas baik di rumah maupun di sekolah, cenderung berteriak ketika ada yang tidak disukainya, mengamuk dan melempar barang. Prestasi F, Claire dan Alex adalah baik tetapi sangat buruk dalam hubungan interpersonal bahkan Alex sudah dua kali pindah sekolah. Mereka kerap mengganggu teman, mendorong dan menabrak teman ketika berjalan, dan semua subjek menunjukkan perkembangan emosional yang tidak stabil dan perubahan mood yang drastis serta pengendalian diri yang buruk. Eric berani mengamuk di depan guru dan mengeluarkan kata-kata kasar, sementara Marco sering berbuat onar dengan nilai tidak memuaskan di sekolah. Jadi pola perilaku yang ditunjukkan subjek studi kasus ini konsisten dengan pola perilaku ODD seperti sering lepas kendali terhadap emosi, berdebat dengan orang dewasa, secara aktif menolak peraturan, secara sengaja mengganggu orang lain, menyalahkan orang lain, merasa sensitif, sering marah.

Penyebab ODD tidak dibahas dalam kasus literatur tetapi pola pengasuhan dan ketidak konsisten orang tua boleh jadi menjadi pemicu parahnya kondisi anak ODD. 
Dinamika ODD menunjukkan bahwa latar belakang keluarga yang tidak kondusif memengaruhi munculnya perilaku membangkang dari anak. Orang tua yang sering melakukan kekerasan fisik kepada anaknya, maka anak itu akan menjadikan dasar pembenaran bahwa kekerasan bisa dilakukan. Demikian juga dengan kondisi orang tua yang terlalu sibuk dengan pekerjaan sehingga membuat anaknya merasa tertinggal dan kurang merasakan pengalaman kasih sayang yang utuh. Anak tunggal biasanya mengalami kekurang pekaan terhadap tingkat emosional yang tidak stabil. Anak yang diasuh oleh nenek atau kakeknya kerap mengalami kebingungan karena pola pengasuhan yang tumpang tindih antara ayah dan ibu dengan nenek kakek atau keluarga lain. Orang tua yang tidak komitmen dan konsisten dalam menerapkan aturan pembinaan anak akan berdampak pada perilaku anak yang tidak disiplin.

Penanganan yang dilakukan pada kasus literatur adalah parent management training di mana pelatihan ini menitikberatkan pada perubahan perspektif orang tua, pemahaman terhadap pola perilaku ODD, serta mengubah reaksi yang diberikan kepada anak ODD. Jika anak itu melakukan sesuai yang baik, maka wajib diberi apresiasi. Upaya untuk mengubah perilaku anak ODD perlu melibatkan kesadaran semua anggota keluarga dan memiliki komitmen bersama untuk mengarahkan anak pada perilaku yang positif dan menjauh dari ciri-ciri gangguan ODD.

Hasil pemeriksaan psikologis, ditemukan bahwa tingkat kecerdasarn intelektual $\mathrm{F}$ berada pada tingkat rata-rata jika dibandingkan dengan kelompok usianya $(I Q=107)$. Tingkat IQ F didukung oleh daya tanggap yang baik terhadap instruksi yang diberikan dan menunjukkan adanya logika berpikir yang cukup seperti pada gambaran pada kasus. Sikap F kurang mendukung apalagi ia menemui tugas yang sulit, tetapi jika tugas cukup mudah maka dia bersungguh-sungguh mengerjakan. Reaksi yang tegas dengan respons negatif mengatakan "tidak tahu" jika ada tugas yang dirasa sulit. Sikap di rumah dan di sekolah yang suka berperilaku menantang dan semaunya itu pun dirasakan sebagai bagian dari kondisi yang tidak mendukung bagi seorang anak yang dianggap tanpa gangguan.

Anak F ini didiagnosis memiliki gangguan ODD oleh psikolog dan hasil interaksi yang dilakukan dalam proses wawancara dan melibatkan dia dalam berbagai aktivitas. Kondisi F menunjukkan bahwa dia sulit menyesuaikan diri dengan lingkungan sosial dan bahkan kerap kali ia bersikap agresif terhadap orang lain dan berlawanan dengan peraturan yang ada. Kondisi ini membuat dia ditakuti teman sebayanya, suka menyendiri tanpa teman-teman. Nampak bahwa F ini memiliki mitos sebagai anak tunggal yang sulit bersosialisasi dan antisosial (Julianto Simanjuntak dan Roswhita Ndraha, 2007).

Menurut Pickhardt (1997) sebagaimana dikutip oleh Samantha (2001) bahwa orang tua dari anak tunggal cenderung untuk lebih sering mengalah, menjaga perasaan anak, dan memperlakukannya dengan hati-hati agar tidak menyakitinya. Akibatnya, anak tidak dewasa secara emosional karena tidak memiliki saudara sebagai bagian dari proses pembentukan tingkat emosional anak. Pada sisi lain, 
orang tua juga cenderung menjadi permisif dan protektif yang berlebihan (Samantha, 2001).

Peran orang tua untuk menjaga kedisiplinan seharusnya didasarkan pada pengembangan struktur internal anak yang mengarah pada harga diri yang sehat dan bukan berdasarkan rasa takut atau malu (Bigner, 1994). Jika hasil wawancara menunjukkan bahwa $\mathrm{F}$ diasuh nenek dan kerap kali bertentangan dengan ibunya, tidak konsisten menerapkan aturan, dan bahkan mendapat hukuman fisik. Holden dan Ritchie (1991) mengungkapkan bahwa bentuk kekerasan fisik kepada anak akan dianggap sebagai modal tingkah laku yang tepat oleh anak tersebut. Sehingga jangan salah kalau anak yang sering mendapat kekerasan, maka dia anak bertindak demikian juga dan bahkan menganggap bahwa pola kekerasan fisik ini menjadi salah satu penyelesaian masalah untuk memperoleh keadilan dan menyatakan pendapat. Berdasarkan hasil penelitian ini dapat diuraikan dinamika ODD pada F seperti gambar berikut.

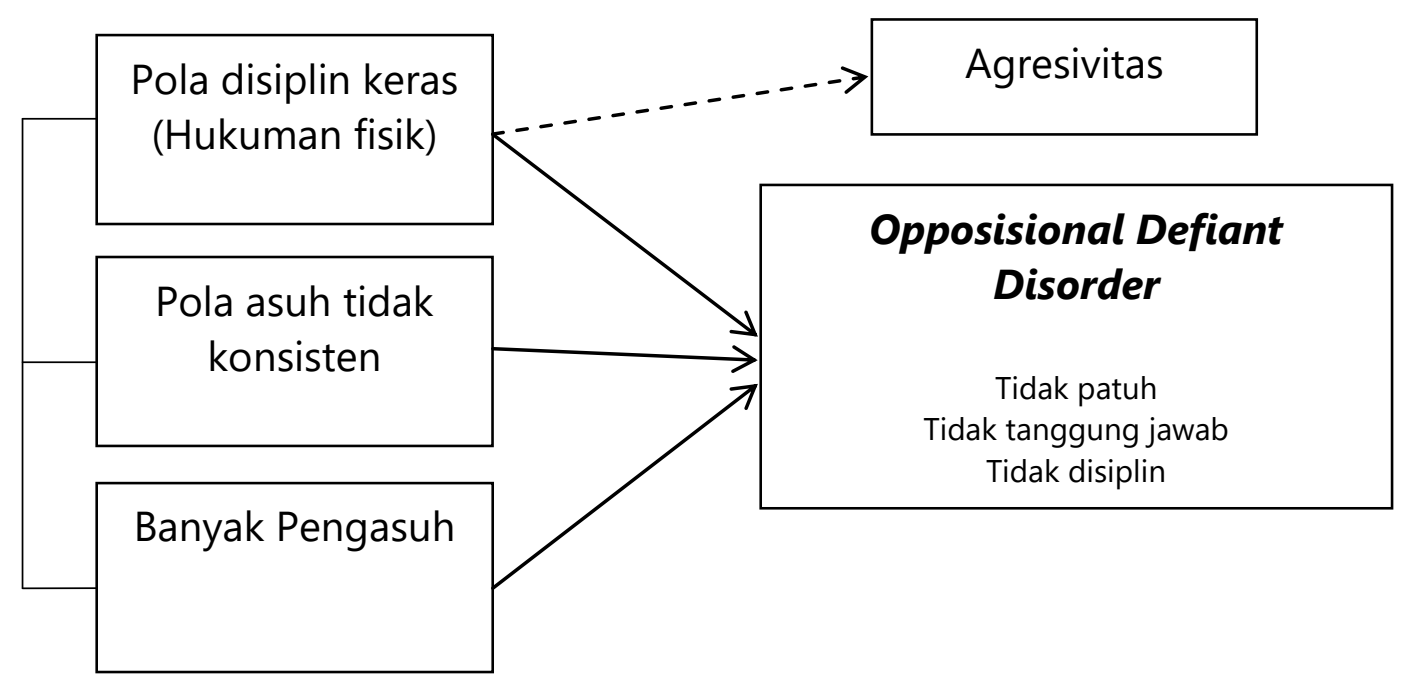

Gambar 2. Pola Dinamika ODD pada F

\section{KESIMPULAN}

Artikel ini dapat menyimpulkan bahwa gangguan ODD lebih sering ditemukan pada anak laki-laki dan tidak tergantung pada urutan struktur keluarga. Pola perilaku mereka menunjukkan perlawanan kepada otoritas baik orang tua maupun guru di sekolah. Subjek $\mathrm{F}$ dan kelima kasus dari data literatur menunjukkan perilaku yang tidak menyukai peraturan, perkembangan emosional yang tidak stabil, dan pengendalian di yang buruk. Solusi penanganan anak yang mengalami gangguan ini adalah memberikan pelatihan kepada orang tua, orang tua membuat aturan yang diterapkan secara konsisten, orang tua memberi penghargaan, dan melibatkan seluruh anggota keluarga dengan perspektif yang sama. Kajian ini masih perlu melibatkan beberapa subjek yang langsung diamati kasusnya sehingga mendapatkan data yang mampu menghasilkan informasi yang lebih lengkap. 


\section{KEPUSTAKAAN}

Alurmei, Wahyu Aulizalsini. (2019). Intervensi Anak ODD di Sekolah Al Falaah Tangerang Selatan. Jurnal Mitra Pendidikan (JMP Online), 3(3), 315-325. http://ejurnalmitrapendidikan.com/index.php/e-jmp/article/view/507.

American Psychiatric Association. (2000). Diagnostic and Statistical Manual of Mental Disorders, 4th Edition, Text Revision, USA.

Ang, Rebecca P. (2004). Asian Secondary School Students' Help-Seeking Behaviour and Preferences for Counsellor Characteristics. Pastoral Care in Education, 22(4), 40-48.

https://web.archive.org/web/20100216074542id_http://www.cpcentre.co.uk:80/ bkp/v2/articles/AsianSecondarySchool.pdf.

Banister, P. Burman, E., Parker, I. Taylor, M., dan Tindall, C. (1994). Qualitative Methods in Psychology, A Research Guide. USA: Open University Press,

Bigner, J. J. (1994). Parent child relations: An introduction to parenting (fourth edition). New Jersey: Prentice Hall.

Caspi, A., Henry, B., McGee, R. O., Moffitt, T. E., \& Silva, P. A. (1995). Temperamental origins of child and adolescent behavior problems: From age three to fifteen. Child Development, 66(1), 55-68. https://doi.org/10.2307/1131190.

Corey, G. (terjemahan Koswara, E. 2009). Teori dan Praktek Konseling dan Psikologi. Bandung: PT. Refika Aditama,.

Costin, J. dan Chambers, S. (2007). Parent Management Training as a Treatment for Children with Oppositional Defiant Disorder Referred to a Mental Health Clinic. Clinical Child Psychology and Psychiatry. Clin Child Psychol Psychiatry, 12(4), 511-524. DOI: 10.1177/1359104507080979.

Creswell, J. W. (2014). Qualitative Inquiry and Research Design: Choosing Among Five Tradition. London: SAGE Publications,

. (2013). Research Design: Quantitative, Qualitative, and Mixed Methods Approaches, Second Edition. Loncon: SAGE Publications.

Crick, N. R., \& Dodge, K. A. (1994). A review and reformulation of social informationprocessing mechanisms in children's social adjustment. Psychological Bulletin, 115(1), 74-101. https://doi.org/10.1037/0033-2909.115.1.74.

Farrington, D. P. (1989). Early predictors of adolescent aggression and adult violence. Violence and Victims, 4(2), 79-100. https://psycnet.apa.org/record/1989-39618-001.

Fraser, Anne. (2008). Oppositional Defiant Disorder. Australian Family Physician, 37(5), 402-405. https://www.racgp.org.au/afp/200806/200806fraser.pdf.

Frick, Paul J., dkk. (1993). Oppositional defiant disorder and conduct disorder: A metaanalytic review of factor analyses and cross-validation in a clinic sample. Clinical Psychology Review, 13(4), 319-340. https://doi.org/10.1016/0272-

7358(93)90016-F. 
Ghosh, Abhishek, Anirban Ray \& Aniruddha Basu. (2017). Oppositional Defiant Disorder: Current Insight. Psychology Research and Behavior Management, 10, 353-367. DOI: 10.2147/PRBM.S120582.

Gunarsa, Yulia Singgih. (2012). Psikologi Anak Bermasalah. Jakarta: Penerbit Libri.

Henry, B., Caspi, A., Moffitt, T. E., \& Silva, P. A. (1996). Temperamental and familial predictors of violent and nonviolent criminal convictions: Age 3 to age 18. Developmental Psychology, 32(4), 614-623. https://doi.org/10.1037/00121649.32.4.614.

Hinshaw, S. P., \& Anderson, C. A. (1996). Conduct and oppositional defiant disorders. In E. J. Mash \& R. A. Barkley (Eds.), Child psychopathology (pp. 113-149). Guilford Press.

Holden, G. W., \& Ritchie, K. L. (1991). Linking extreme marital discord, child rearing, and child behavior problems: Evidence from battered women. Child Development, 62(2), 311-327. https://doi.org/10.2307/1131005.

Jones, Sara H. (2017). Oppositional Defiant Disorder: An Overview and Strategies for Educators. General Music Today, 31(2), 12-16. DOI: 10.1177/1048371317708326.

Kane, Anthony. (2009). Oppositional Difiant Disorder. https://mental-healthmatters.com/oppositional-defiant-disorder/\#Treatment.

Kane, P \& J. Garber. (2004), The relations among depression in fathers, children's psychopathology, and father-child conflict: A meta-analysis. Clinical Psychology Review, 24(3). 339-360.

https://www.sciencedirect.com/science/article/abs/pii/S0272735804000443.

Lahey, B. B., Applegate, B., McBurnett, K., Biederman, J., Greenhill, L., Hynd, G. W., Barkley, R. A., Newcorn, J., Jensen, P., \& Richters, J. (1994). DSM-IV field trials for attention deficit hyperactivity disorder in children and adolescents. The American journal of psychiatry, 151(11), 1673-1685.

https://doi.org/10.1176/ajp.151.11.1673.

Lester, A. D. (2002). Pelayanan Pastoral bersama Anak-anak dalam Krisis (terjemahan). Malang: Depertemen Literatur SAAT.

Mash, E. J. \& D. A. Wolfe. (1999). Abnormal Child Psychology. USA: Wadsworth.

Mikolajewski, Amy J., Jeanette Taylor, \& William G. Iacono. (2017). Oppositional Defiant Disorder Dimensions: Genetic Influences and Risk For Later Psychopathology. Journal of Child Psychology and Psychiatry, 58(6), 702-710. DOI: $10.1111 /$ jcpp.12683.

Nixon, B. (2009). The Birth to Five Book: Confident Childrearing Right from the Start. MI, USA: Revell Books.

Patton, M. Q. (1990). Qualitative evaluation and research methods (2nd ed.). Sage Publications, Inc.

Raine, A. (1993). The psychopathology of crime: Criminal behavior as a clinical disorder. Academic Press. https://doi.org/10.1016/B978-0-08-057148-5.50005-8.

Ridha, Andi Ahmad. (2020). Metode Positive Behavior Support untuk Mengelola Emosi dan Perilaku pada Anak dengan Oppositional Defiant Disorder. Jurnal 
Psikologi dan Kesehatan Mental, 5(2), 150-161. DOI:

10.20473/jpkm.v5i22020.150-161.

Rochmah, Khanifatur. (2018). Studi Kasus Perilaku Anak Oppositional Defiant Disorder

Di SDN Panggang. Basic Education, 7(40), 3.938-3945.

http://journal.student.uny.ac.id/ojs/index.php/pgsd/article/view/14098.

Rothenberg, Amy. (2013). Oppositional Defiant Disorder: A Case of Platinum

metallicum. https://www.nhcmed.com/further-reading/topic-cycles-and-

segments-cases/oppositional-defiant-disorder-a-case-of-platinum-

metallicum.html.

Samantha, Febiani L. (2001). Gambaran Kesendirian dan Implikasinya terhadap Kesepian pada Anak Tunggal. Depok: Universitas Indonesia.

Sanjiwani, Anak Agung Sri, Tri Kurniati Ambarini, dan I. G. A. Putu Wulan Budisetyani.

Dinamika psikologis remaja dengan gangguan sikap menentang yang tinggal di panti asuhan. Jurnal Psikologi Udayana, 7(1), 1-9.

https://doi.org/10.24843/JPU.2020.v07.i01.p01.

Schoorl, Jantiene, dkk. (2016). Emotion Regulation Difficulties in Boys with Oppositional Defiant Disorder/Conduct Disorder and the Relation with Comorbid Autism Traits and Attention Deficit Traits. PLOS ONE, 11(7), 1-12. DOI: 10.1371/journal.pone.0159323.

Selman, R., Beardslee, W., Schultz, L., Krupa, M., \& Podorefsky, D. (1986). Assessing adolescents interpersonal negotiation strategies: Toward integration of structural and functional models. Developmental Psychology, 22(4), 450 - 459.

Selman, Bart, Hector Levesque, David Mitchell. (1992). A New Method for Solving Hard Satisfiability Problems. AAAI-92 Proceedings.

Simanjuntak, Julianto dan Ndraha, Roswitha. (2007). Mendidik Anak Sesuai Zaman dan Kemampuannya. Tangerang: Yayasan Konseling Keluarga dan Karier (LK3).

Soriano, M. (2006). Case Study: Oppositional Defiant Disorder. New Jersey, USA: Morris Country EduCare.

Stamps, D. C. (1994). Alkitab Penuntun Hidup Berkelimpahan. Malang: Gandum Mas,

Surbakti, E. B. (2012). Parenting Anak-anak. Jakarta: PT. Elex media Komputindo. 